\title{
A Comparison of the Effects of Different Equipment used for Venipuncture to Aid in Promoting More Effective Simulation Education
}

\section{Chieko Fujii ${ }^{*}$, Hiroyuki Ishii ${ }^{2}$ and Atsuo Takanishi ${ }^{3}$}

${ }^{1}$ Faculty of Nursing and Medical Care, Keio University, Endo4411 Fujisawa City, Kanagawa, 252-0883, Japan

${ }^{2}$ Research Institute for Science and Engineering, Waseda University, Tokyo, Japan

${ }^{3}$ Faculty of Science and Engineering, Waseda University, Tokyo, Japan

\begin{abstract}
Patient safety during venipuncture is of utmost importance. In Japan, good venipuncture practices are developed in nursing schools and hospitals by the use of educational simulators. This study examined techniques used by experienced nurses to educate nursing students and nurses on venipuncture techniques.

Forty-four nurses completed a questionnaire and were videotaped during venipuncture performed on a mode of a simulated arm that we had developed. Using software to analyze motion and movement along the X-Y coordinates, we measured puncture angles and distance travelled by the needle using a $20 \mathrm{ml}$ syringe, other syringe sizes, and vacuum tubes. Needle and hand movement were also examined.

Venipuncture requires a point of a vein to be identified and insertion of a needle into that puncture site Simulation training may assist to consciously avoid unnecessary movements caused by hand rotation and also emphasizes the importance of learning the basic movements for needle insertion. It is important that educational methods and evaluation are linked and developed using an appropriate simulator of the venipuncture technique.
\end{abstract}

Keywords: Motion analysis; Needle movement; Nursing practice; Simulation; Skill evaluation

\section{Introduction}

Prior to performing venipuncture in clinical practice a controlled environment needs to be established under the direction and supervision of clinical experts [1]. Recently, nursing students have numerous opportunities to practice their skill without causing harm to patients [2], with the prelicense nursing curriculum examining patient safety and quality concerns [3]. Simulated learning in a clinical skills center has become popular in undergraduate nursing education. Simulation provides a positive learning experience in which students can refine their patient management skills [4].

Since 2002, the Health Policy Bureau of the Ministry of Health, Labour and Welfare in Japan has regarded intravenous injections as part of the role of nurses. Venipuncture was included with these injections as some nurses were also responsible for collection of blood samples. The safety of patients was also regarded as important.

Nursing students may not get the opportunity to perform a venipuncture on a patient, with a simulator providing the opportunity to practice the technique before carrying it out in the hospital environment. In hospitals offering educational programs, retraining may also act as an added incentive for nurses considering employment. Venipuncture techniques are also taught using simulators in both nursing schools and hospitals.

Many academic and healthcare settings currently use simulation to allow students to exercise their knowledge and skills in a virtual clinical setting [5]. Developing clinical skills, first through simulation and then through patient clinical care, is extremely valuable [6]. Highfidelity patient simulation is becoming increasingly integral to nursing education [7]. Training programs for intravenous catheter placement generally use plastic arm models, although the lack of anatomic variability and variable design of these models can diminish the educational experience for students [8]. However, numerous forearm models are constructed so that they can be deployed in limited spaces and are therefore easy to use for simultaneous group training sessions. To achieve this objective, simulators must be used effectively. After choosing the most suitable simulator, it is important to determine how to establish the best learning environment and also how we evaluate venipuncture technique. Further research is required to assess the effectiveness of patient simulation in achieving learning objectives and clinical competence [9]. It has also been suggested that the rigor and quality of this research should be improved [10].

For venipuncture it is necessary to consider the angles the skin is punctured and the needle enters the vein. Still image showed that after the needle tip touched the skin, $77 \%$ of participants raised or lowered the needle relative to a straight trajectory [11]. Although textbook and instructors of venipuncture generally cite puncture angles of approximately $20^{\circ}$ or less, published empirical evidence is lacking. To reduce the risk of nerve damage, it is necessary to understand how different-sized equipment affects the length of needle entry. It appears that awareness and knowledge on potential differences in puncture angle and inward movement of the needle tip may lead to safer practices, even when different types of equipment are used.

It is necessary to explain the venipuncture technique of experienced nurses using a simulator and whether there are differences in the devices used and how the technique is evaluated. This study aimed to examine techniques used by nurses who regularly perform venipuncture, so that

*Corresponding author: Chieko Fujii, Faculty of Nursing and Medical Care, Keio University Endo4411 Fujisawa City, Kanagawa, 252-0883, Japan, Tel: +81 466-49-6218; E-mail: chieko@sfc.keio.ac.jp

Received June 03, 2014; Accepted Auguste 31, 2014; Published September 05, 2014

Citation: Fujii C, Ishii H, Takanishi A (2014) A Comparison of the Effects of Different Equipment used for Venipuncture to Aid in Promoting More Effective Simulation Education. J Blood Disorders Transf 5: 228. doi: 10.4172/2155-9864.1000228

Copyright: (c) 2014 Fujii C, et al. This is an open-access article distributed under the terms of the Creative Commons Attribution License, which permits unrestricted use, distribution, and reproduction in any medium, provided the original author and source are credited. 
effective methods can be developed to educate nursing students and nurses who are still learning venipuncture techniques.

\section{Methods}

\section{Study population}

The study was performed in a metropolitan hospital in Japan over a three-day period in August 2010. Forty-four nurses who were able to spend $30 \mathrm{~min}$ away from work each day for 3 days were enrolled in the study. The 44 participants had a mean age ( \pm standard deviation) of $36.6 \pm 9.4$ years and $12.0 \pm 8.9$ years of nursing practice. Thirty-five participants $(79.5 \%)$ had performed venipunctures during the first year of their employment.

Ethical approval was obtained from the ethics committee of the Graduate School of Health Management, Keio University. The participants were provided with an explanation of the study objectives and were informed they would not be penalized for withdrawing from the study.

\section{Data collection}

The Waseda Kyotokagaku Skin No.2 Refined II; WKS-2RII model [12] was used to imitate surgical procedures and provide quantitative information on the learning progress of the trainees. We modified the model to assess venipuncture techniques so that it represented a model for puncturing the skin. The vascular model consisted of simulated skin and veins placed on a urethane base and provided a replicate of the cubital region. The simulated vein had an external diameter of $3 \mathrm{~mm}$ and internal diameter of $2 \mathrm{~mm}$, and was located between models of fat (8-mm-thick urethane foam) and skin (2.0-2.5-mm-thick silicone). The nurses confirmed that the vein could be palpated through the skin surface.

Some images were unusable due to excess hand movement and therefore the number of venipunctures was different between nurses. The number that we were able to analyze as a picture was as follows: a total of 191 venipunctures were performed by 44 nurses using a $20 \mathrm{ml}$ syringe, with 32 performing 5 punctures and 4 performing 4 punctures. Unusable moving images were excluded from the analyses. For vacuum tube sampling, 30 nurses performed 5 punctures, 2 nurses performed 2-4 punctures each, and 3 nurses performed 3 punctures, making a total of 171 punctures.

The nurses were requested to perform each technique using both a $10 \mathrm{ml}$ and $2.5 \mathrm{ml}$ syringe. The raw data of film footage of 39 subjects were analyzed.

\section{Venipuncture device}

The nurse was required to choose the size of the syringe according to the volume of blood required for the clinical situation. The following syringes and injection needles were therefore used: $20 \mathrm{ml}$, SS-20ESZ, diameter $(\Phi) 21.7 \mathrm{~mm} ; 10 \mathrm{ml}$ SS-10ESZ, $\Phi 17.2 \mathrm{~mm}$ or $2.5 \mathrm{ml} \mathrm{SS}-02 S Z$, $\Phi 10.0 \mathrm{~mm}$; 21-gauge SB needle (NN-2138S); Terumo Corporation, Tokyo, Japan). A vacuum tube holder (XX-VP010HD01 inside diameter $20 \mathrm{~mm}$ ) and straight needles (21 gauge, MN-HD2138MS) were used for the evacuation tube collection system. These devices are used commonly in Japan, and are currently used at the facilities where the surveys were carried out.

\section{Data processing procedure and analysis}

\section{Photographing}

A Digital HD Video camera recorder (HDR-HC9, Sony, Japan) mounted on a tripod and hi-vision mini-DV tapes were used for recording the procedures. The maximum telephoto zoom (10 times) allowed a distance of $50 \mathrm{~cm}$ from the camera lens to the puncture point.

\section{Preparation of the AVI file}

The video recordings were captured using video editing software EDIUS Pro 5 (Grass Valley, K.K., Japan). The frame rate of the AVI file was 59.94 frames/ second. To facilitate the acquisition process, we then converted these files into 24-bit true color using a video capture of 720 $\mathrm{x} 480$ pixels whilst matching them on a monitor.

\section{Analysis of images}

WINanalyze software (Mikromak GmbH, Germany, and Agency of Bertec Japan) tracks objects without markers, and assists in analyzing movements on video recordings. This software is suitable for Windows AVI. A solid-state drive (SSD)-correlation tracking algorithm was activated during acquisition to adapt the quality of the image sequence and account for differences in color. Coordinate points for $\mathrm{X}$ and $\mathrm{Y}$ in each frame were created by WINanalyze. An advantage of the software was that the needle could be kept aseptic.

\section{Data analysis}

Data obtained from the $\mathrm{X}$ and $\mathrm{Y}$ coordinates were saved in Excel (Microsoft Corporation, USA, Japanese edition) and analyzed using SPSS software (SPSS 19.0 for Windows; IBM, Japan). Unpaired t-tests were used to examine intergroup differences (e.g., $20 \mathrm{ml}$ syringe vs. (1) vacuum tube (2) $10 \mathrm{ml}$ syringe and (3) $2.5 \mathrm{ml}$ syringe). Student's t-test was applied when homoscedasticity was demonstrated, with Welch's t-test being used in these cases. P values $<0.05$ were considered statistically significant

\section{Tracking Points}

Figure 1 shows the points for easiest tracking.

Point A: Contact between the needle and model. This frame was designated as Time (a).

Point B: Needle movement with the welded part and hub of the needle being cream color for easy recognition.

Point C: Hand movement. Metacarpophalangeal joint (MP joint) of the first or second fingers.

Time (b) was the frame showing cessation of needle movement.

\section{Observation Endpoints}

\section{Calculation of time}

The number of frames from time (b) to time (a) in the AVI file was counted using a frame rate of 59.94 frames/second, with the total being reduced by 1 .

\section{Calculation of distance between multiple punctures}

We used the formula of the trigonometric function using two coordinates. The difference between puncture points during multiple punctures was also determined. Multiple punctures were performed using either a $20 \mathrm{ml}$ syringe or vacuum tube. The distances between puncture Point $\mathrm{A}$ and the next puncture point, and the final and first puncture points were calculated for each nurse. The length of the needle was kept constant. However, the distance in each picture was not always the same, with the calculation bias corrected using needle 


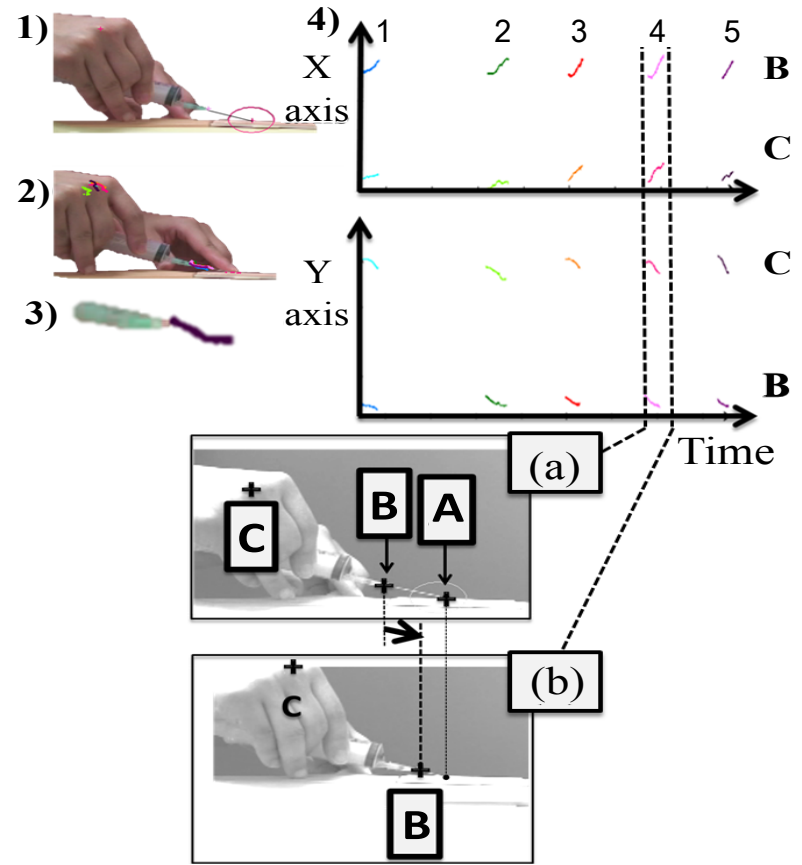

Figure 1: Image sequence function and connection points that result in the easiest tracking

1) Connections, 2) Objects in all frames, 3) Objects in a frame, 4) X- and $Y$-coordinates on the vertical axis and time on the horizontal axis

Point A: The needle makes contact with the model; designated as time (a). Point B: Needle movement; the welded part of the needle and the needle hub.

Point C: Hand movement; the metatarsophalangeal joint of the first or second finger. Time (b): Cessation of needle movement.

length.

\section{Calculation of angle}

The angle of points $\mathrm{B}$ and $\mathrm{C}$ relative to point $\mathrm{A}$ was calculated using a formula that included the two coordinates.

$\mathrm{X}$ axis and $\mathrm{Y}$ axis movement: This study measured changes in angle visually on the WINanalyze screen which displayed a graph using a 20 $\mathrm{ml}$ syringe. We also carried out abstraction using symbolic description. The movements were analyzed after assigning indicators, namely, I, V, $\Lambda$ (Greek character lambda), N, И (Russian character "ee"), M, and W, that corresponded to the shapes formed by the movements.

\section{Results}

\section{Differences using the equipment}

Table 1 shows the differences in duration of blood sampling using a $20 \mathrm{ml}$ syringe ( $2.5 \pm 1.0$ seconds), vacuum tube, and $2.5 \mathrm{ml}$ and $10 \mathrm{ml}$ syringes. Once the needle tip made contact with the model, the time from puncture to cessation of movement was longest using the $10 \mathrm{ml}$ syringe $(2.9 \pm 1.3$ seconds; $P=0.038)$.

After making the puncture, the average distance travelled by the needle was $15.4 \pm 3.8 \mathrm{~mm}$ for the $2.5 \mathrm{ml}$ syringe and $14.9 \pm 4.7$ with the $10 \mathrm{ml}$ syringe. Both distances exceeded the average distance travelled by the needle using a $20 \mathrm{ml}$ syringe $(12.1 \pm 4.5 \mathrm{~mm})$. Significant differences were observed between distances travelled by the needle using $10 \mathrm{ml}(\mathrm{P}=0.001)$ and $2.5 \mathrm{ml}$ syringes $(P<0.001)$ compared with the $20 \mathrm{ml}$ syringe. The mean puncture angle was $14.2^{\circ} \pm 6.3^{\circ}$ with the 20 $\mathrm{ml}$ syringe and $17.4^{\circ} \pm 5.1^{\circ}$ with the vacuum tube. This difference was statistically significant $(P<0.001)$. The angle between the MP joint and puncture site was significantly different between the $20 \mathrm{ml}$ syringe $28.9^{\circ}$ $\pm 10.4^{\circ}$ and both the vacuum tube $\left(36.1^{\circ} \pm 8.6^{\circ} ; P<0.001\right)$ and $2.5 \mathrm{ml}$ syringe $\left(32.8^{\circ} \pm 10.2^{\circ} ; P=0.033\right)$. The maximum angle observed during puncture with a $20 \mathrm{ml}$ syringe was $55.6^{\circ}$.

Assessment of angle changes at times (a) and (b) showed that compared to time (a) when the needle tip touched the model, the needle joint angle decreased at time (b) after the needle had been moved. However, the angle of the MP joint increased. To calculate differences in puncture points during multiple punctures, the study averaged the differences in positions for subjects who attempted multiple trials with the $20 \mathrm{ml}$ syringe and vacuum tube. The mean difference for the 20 $\mathrm{ml}$ syringe was $5.0 \mathrm{~mm}$, with a maximum value of $21.4 \mathrm{~mm}$, while the mean difference for the vacuum tube was $3.9 \mathrm{~mm}$. This demonstrated the $20 \mathrm{ml}$ syringe resulted in significantly greater changes in position $(P=0.006)$

\section{Example showing the movement of various needles}

Figure 2 shows the $20 \mathrm{ml}$ syringe technique with five puncture points grouped in close proximity. For procedures resulting in five punctures, the distance from the previous to subsequent puncture was measured using the coordinate points, and the mean distance calculated. The mean distance observed in the target film footage of closely grouped puncture points, identified by the image sequence function using objects from all frames, was $1.1 \mathrm{~mm}$ with the $20 \mathrm{ml}$ syringe. Although the puncture points were the same, needle and MP joint movements appeared inconsistent. When making the fourth puncture, movements were observed four times in both the X-and $\mathrm{Y}$-axes. However, the needle did not move in a diagonal direction, with the needle and MP joint movements differing.

\section{Classification of needle movement}

Table 2 shows the comparison of frequency of needle movements categorized by symbolic descriptors. Horizontal movements along the $\mathrm{X}$-axis occurred up to 5 times or more, whereas vertical movements along the $\mathrm{Y}$-axis entailed 1 to 4 changes in movement. At the welded part of the needle, movement in the $\mathrm{X}$-axis was characterized by $I$, whereas movement in the $\mathrm{Y}$-axis was characterized by $I$ in $24.6 \%, V$ in $4.2 \%, \Lambda$ in $13.6 \%, N$ in $1.6 \%$, and $U$ in $22.0 \%$ of cases. $\mathrm{X}$-axis movement was $I$ or $V$, and Y-axis movement, enclosed with bold lines, was $I, V$, $\Lambda, N$, or $U$ in $72.8 \%$ of cases at the welded part of the needle and $36.1 \%$ at the MP joint.

\section{Data showing needle movement in a large proportion of the venipunctures}

Figure 3 shows a large proportion of needle movement due to combined movement in the X-and Y-axes. Nearly $44 \%$ of X-and $Y$-axis movements at the MP joint consisted of combinations of I and $\Lambda$, I and I, $N$ and $\Lambda$, or $\Lambda$ and $\Lambda$ movements. At the welded part of the needle, $67.5 \%$ of movements in the $\mathrm{X}$ - and $\mathrm{Y}$-axes entailed a combination of I and I, I and $И, \mathrm{I}$ and $\Lambda$, and $\mathrm{N}$ and $И$ movements. These data were derived from photographs of movement at time (a). An Excel database was prepared of coordinate data grouped according to time, and the coordinates superposed on a photograph as needle movement.

\section{Discussion}

\section{Using a simulator to learn skills to ensure patient safety}

Due to the limited availability of clinical sites and shorter hospital 
Citation: Fujii C, Ishii H, Takanishi A (2014) A Comparison of the Effects of Different Equipment used for Venipuncture to Aid in Promoting More Effective Simulation Education. J Blood Disorders Transf 5: 228. doi: 10.4172/2155-9864.1000228

Page 4 of 7

\begin{tabular}{|c|c|c|c|c|c|c|c|c|c|c|c|c|}
\hline & & \multirow{4}{*}{\multicolumn{2}{|c|}{$\begin{array}{l}\text { Vacuum tube holder } \\
\qquad n=171\end{array}$}} & \multirow{2}{*}{\multicolumn{4}{|c|}{ Syringe and injection needle }} & & & \multirow{2}{*}{\multicolumn{3}{|c|}{$\begin{array}{c}\text { Syringe }(20 \mathrm{ml}) \\
\text { Vs. }\end{array}$}} \\
\hline & & & & & & & & & & & & \\
\hline & & & & \multirow{2}{*}{\multicolumn{2}{|c|}{\begin{tabular}{|c|} 
Syringe $(20 \mathrm{ml})$ \\
$\mathrm{n}=191$
\end{tabular}}} & \multirow{2}{*}{\multicolumn{2}{|c|}{$\begin{array}{l}\text { Syringe }(20 \mathrm{ml}) \\
\mathrm{n}=39\end{array}$}} & \multirow{2}{*}{\multicolumn{2}{|c|}{\begin{tabular}{|l} 
Syringe $(20 \mathrm{ml})$ \\
$\mathrm{n}=39$
\end{tabular}}} & \multirow{3}{*}{$\begin{array}{l}\text { Vacuum } \\
\text { Tube holder }\end{array}$} & \multirow{2}{*}{$\begin{array}{l}\text { Syringe } \\
(10 \mathrm{ml})\end{array}$} & \multirow{2}{*}{$\begin{array}{l}\text { Syringe } \\
(2.5 \mathrm{ml})\end{array}$} \\
\hline & & & & & & & & & & & & \\
\hline & & Mean & SD & Mean & SD & Mean & SD & Mean & SD & & P-v & lue \\
\hline \multicolumn{13}{|c|}{ Time from puncture to when movement stopped } \\
\hline \multicolumn{2}{|c|}{ Mean (seconds) } & 2.8 & \multirow{3}{*}{1.3} & 2.5 & \multirow{3}{*}{1.0} & 2.9 & \multirow{3}{*}{1.3} & 2.8 & \multirow{3}{*}{1.0} & \multirow{3}{*}{$0.051 \dagger$} & \multirow{3}{*}{0.038} & \multirow{3}{*}{0.091} \\
\hline Maxir & $m$ (seconds) & 8.8 & & 7.3 & & 8.0 & & 5.5 & & & & \\
\hline Minin & (seconds) & 0.0 & & 0.7 & & 0.0 & & 1.3 & & & & \\
\hline \multicolumn{13}{|c|}{ Distance travelled by needle } \\
\hline Mean & n) & 12.4 & \multirow{3}{*}{4.0} & 12.1 & \multirow{3}{*}{4.5} & 14.9 & \multirow{3}{*}{4.7} & 15.4 & \multirow{3}{*}{3.8} & \multirow{3}{*}{0.586} & \multirow{3}{*}{0.001} & \multirow{3}{*}{$P<0.001$} \\
\hline Maxir & $m(\mathrm{~mm})$ & 21.8 & & 24.6 & & 24.7 & & 24.5 & & & & \\
\hline Minin & $n(m m)$ & 0.2 & & 0.8 & & 0.4 & & 9.3 & & & & \\
\hline \multicolumn{13}{|c|}{ Skin puncture Puncture angle } \\
\hline & Mean $\left({ }^{\circ}\right)$ & 17.4 & & 14.2 & & 13.9 & & 15.9 & & & & \\
\hline a) $\ddagger$ & Maximum $\left({ }^{\circ}\right)$ & 44.7 & 5.1 & 55.6 & 6.3 & 36.1 & 6.1 & 30.3 & 5.6 & $P<0.001$ & 0.782 & 0.137 \\
\hline a) + & Minimum $\left({ }^{\circ}\right)$ & 9.7 & 0.1 & 2.8 & 0.0 & 5.3 & & 6.4 & 0.0 & $r=0.001$ & 0.102 & 0.101 \\
\hline & Mean $\left({ }^{\circ}\right)$ & 14.4 & & 8.6 & & 7.7 & & 10.3 & & & & \\
\hline b) $\S$ & Maximum $\left({ }^{\circ}\right)$ & 30.8 & 49 & 55.3 & 68 & 14.4 & 35 & 44.9 & 72 & $P<0.001$ & 0.376 & 0.156 \\
\hline & Minimum $\left({ }^{\circ}\right)$ & 0.2 & & 0.3 & & 0.4 & & 1.0 & & & & \\
\hline Angl & hanges $(b-a)$ & & & -5.6 & & -6 & & & & & & \\
\hline MP jc & and puncture & & & & & & & & & & & \\
\hline & Mean $\left({ }^{\circ}\right)$ & 36.1 & 86 & 28.9 & & 30.7 & & 32.8 & & & & \\
\hline a) $\ddagger$ & Maximum $\left({ }^{\circ}\right)$ & 65.9 & & 77.1 & 10.4 & 57.2 & 9.4 & 65.2 & 102 & $P<0.001$ & 0.311 & 0.033 \\
\hline & Minimum $\left({ }^{\circ}\right)$ & 17.4 & & 5.4 & & 11.7 & & 18.2 & 10.2 & & & \\
\hline & Mean $\left({ }^{\circ}\right)$ & 39.5 & & 30.0 & & 31.5 & & 35.4 & & & & \\
\hline b) $\S$ & Maximum $\left({ }^{\circ}\right)$ & 63.0 & 9.1 & 76.0 & 9.6 & 48.6 & 8.4 & 69.3 & 9.9 & $P<0,001$ & 0.367 & 0.002 \\
\hline & Minimum $\left({ }^{\circ}\right)$ & 18.0 & & 6.6 & & 3.8 & & 18.4 & & & & \\
\hline Angl & hanges (b-a) & & & 1. & & & & & & & & \\
\hline Diffe & ces in punctur & & & & & & & & & & & \\
\hline $\begin{array}{l}\text { Mean } \\
\text { Maxir }\end{array}$ & $m\left({ }^{\circ}\right)$ & $\begin{array}{l}3.9 \\
8.8\end{array}$ & $\begin{array}{l}3.1 \\
7.9\end{array}$ & $\begin{array}{c}5.0 \\
21.4\end{array}$ & $\begin{array}{l}4.4 \\
6.2\end{array}$ & & & & & & & 006† \\
\hline Minin & $n\left({ }^{\circ}\right)$ & 0.4 & 0.4 & 1.1 & 0.4 & & & & & & & \\
\hline
\end{tabular}

Student t: test $p$-value, $\uparrow:$ Welch's t-test p-value, $\ddagger$ : Time point when the needle come into contact with the model $\S$ : The cessation of needle movement Table 1: Differences in blood sampling using a $20 \mathrm{ml}$ syringe, vacuum tube sampling, and a $10 \mathrm{ml}$ or $2.5 \mathrm{ml}$ syringe.

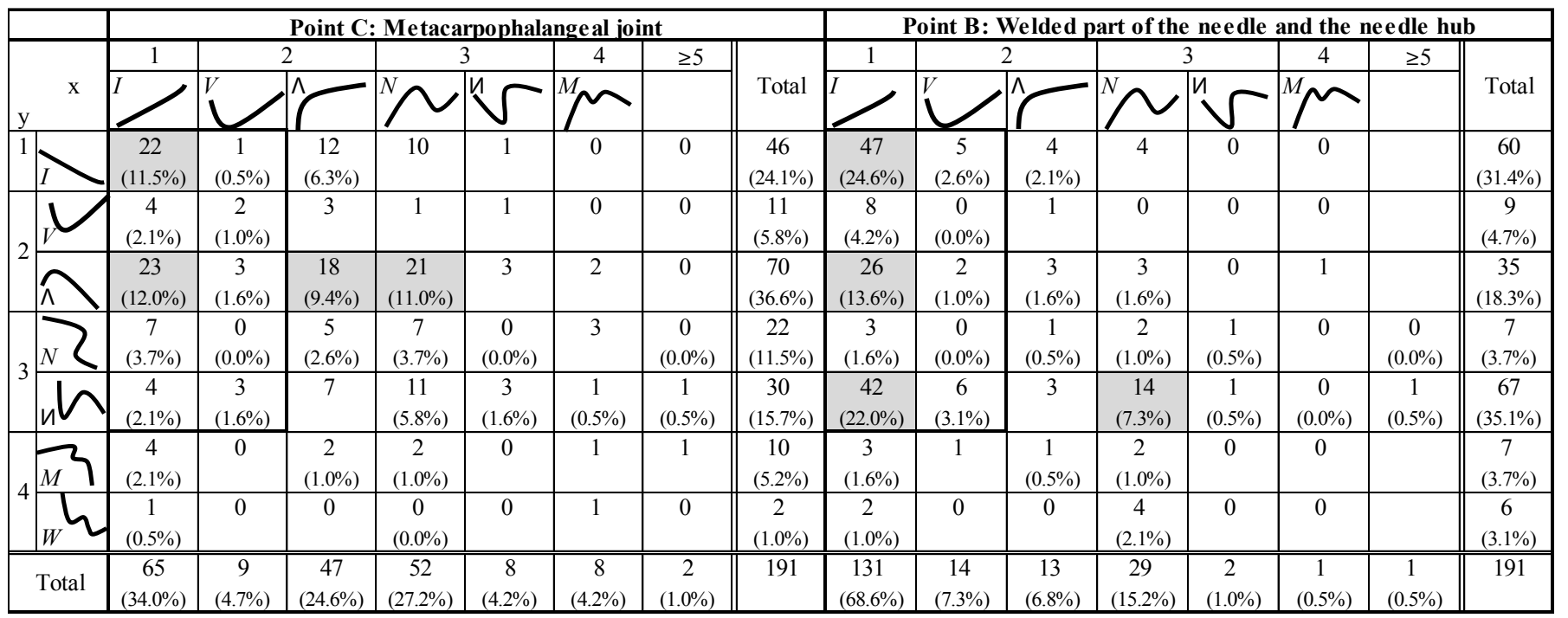

Table 2: Comparsion of frequency of needle movements categorized by symbolic descriptors. 


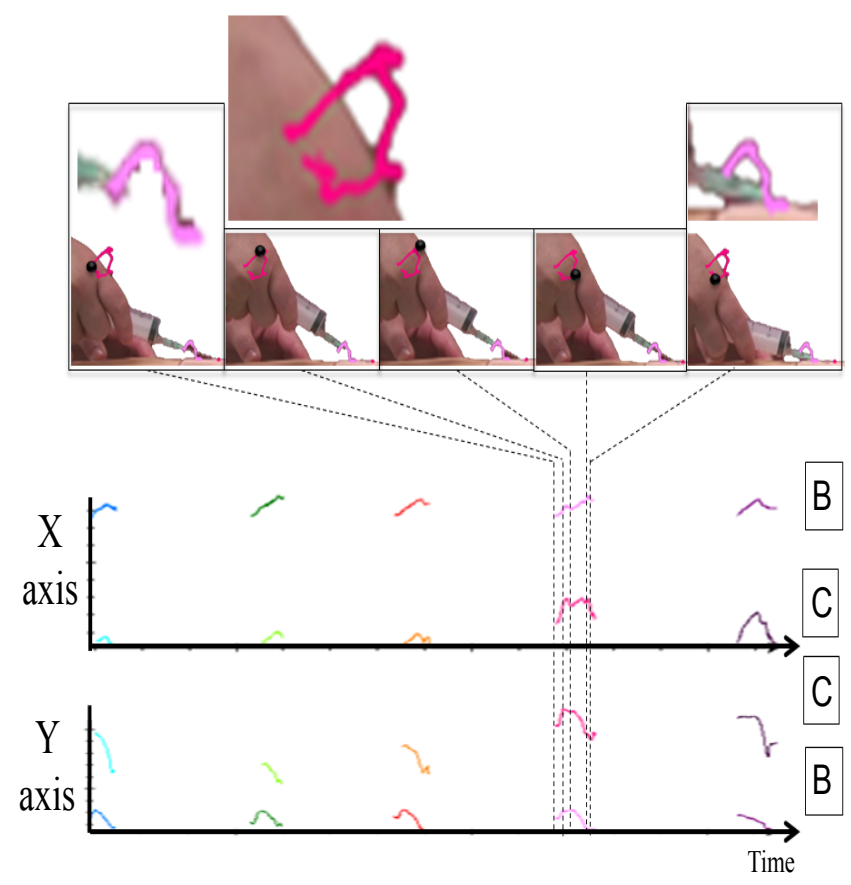

Figure 2: An example of venipuncture using a $20 \mathrm{ml}$ syringe. In this case, five punctures were performed in close proximity. Needle and metatarsophalangeal joint movements were inconsistent and varied particularly during the fourth puncture.

stays, patients now present with more acute and complex healthcare issues and needs [13]. Students are therefore not always able to receive appropriate clinical experience. Nevertheless, patient safety has been emphasized and questions are now being asked regarding the types of training that should be implemented before actual clinical practice. Practical clinical skills lie at the heart of nurses' professional practice. Therefore, mastery of a fundamental clinical skill is an important component of courses leading to registration [14]. An integrated approach for training of clinical skills in undergraduate nursing students is therefore necessary [15]. The use of simulated technology addresses patient safety as students are able to refine their skills and develop competency in this environment [16].

\section{Evaluation using the simulator}

Further work is needed to strengthen the evidence base for the use of simulation models [17]. Simulation-based methods can also be implemented in rural locations to develop emergency medical skills or obstetric first-aid skills for birth attendants [18]. Numerous studies have considered how to use simulators as educational tools.

The plastic arm, however, does not convey pain response feedback by the patient during venipuncture caused by technical mistakes and failure to simulate realistic pressures and touch feedback. Despite this limitation, the students commented on the superiority of the plastic arm and its realistic features regarding arm stability and tourniquet use. Medical and nursing students enjoy and prefer one-on-one training with a faculty member using virtual reality models [8]. Simulationbased healthcare education uses well-defined learning objectives and tasks with an appropriate level of difficulty [19]. Efforts to reduce occupational health and safety risks include staff education, safer equipment, and the reduction of needle-dependent procedures [20].
In this study, we used the simulator to evaluate the venipuncture maneuvers of experienced nurses. The method these experienced nurses used was not necessarily according to the textbook. In particular there were individual differences in three main areas; differences in syringe size and needle movement, and not needling the same point in multiple punctures. It is therefore important to learn how to use different equipment and also to train puncturing the same point with the needle.

\section{Experiment using realistic equipment}

This study was the first to measure the actual angles, and showed mean puncture angle using the same model was $17^{\circ}$ with vacuum tubes, $16^{\circ}$ with $2.5 \mathrm{ml}$ syringes, and $14^{\circ}$ with $20 \mathrm{ml}$ and $10 \mathrm{ml}$ syringes. The

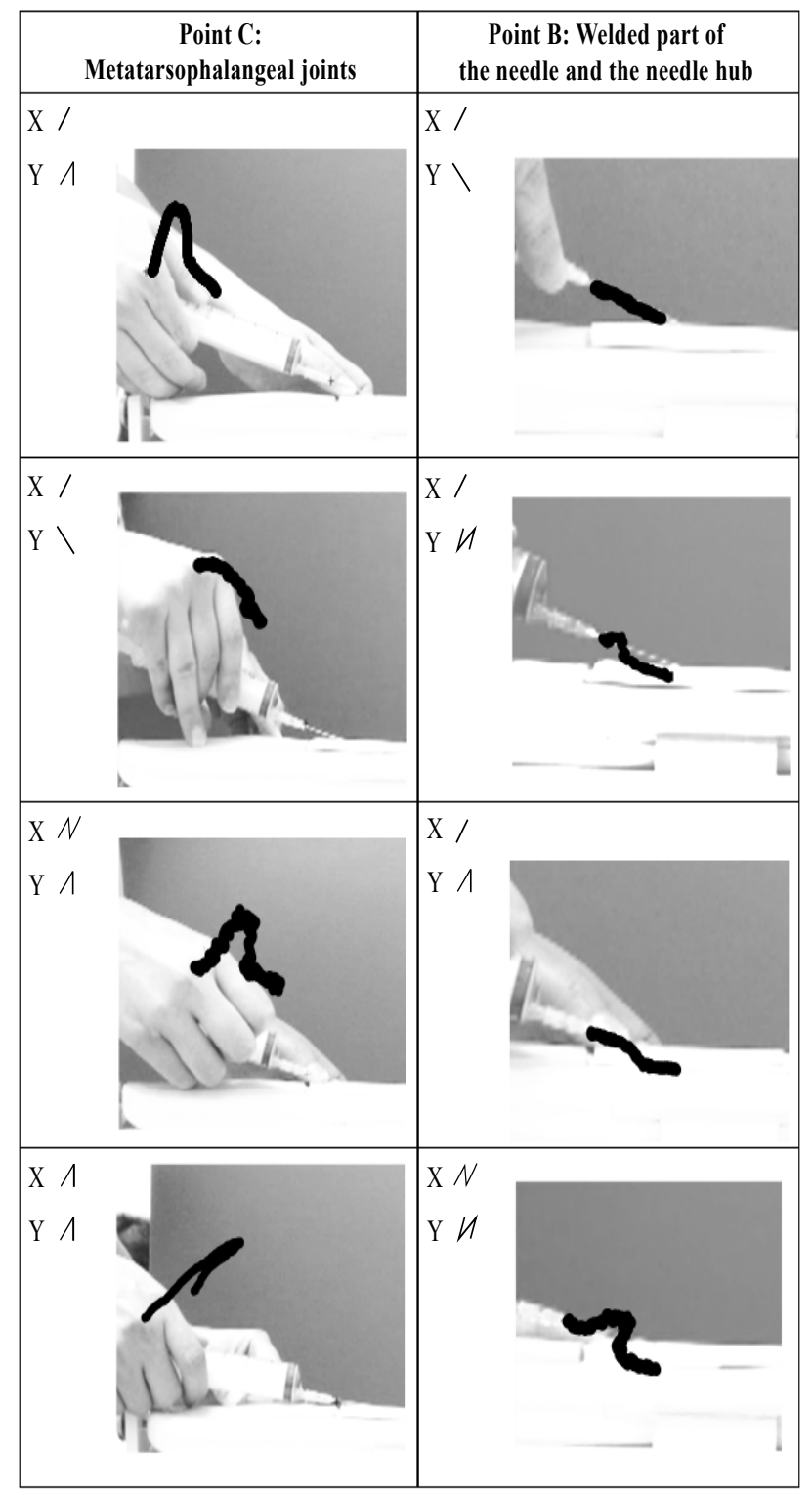

Figure 3: A large proportion of needle movement was due to the combined movements in the $\mathrm{X}$ - and $\mathrm{Y}$-axes. These photographs show the large proportion of needle movement in the $X-Y$ axis at time (a). The coordinates are superposed on a photograph as needle movement using Excel. 
Citation: Fujii C, Ishii H, Takanishi A (2014) A Comparison of the Effects of Different Equipment used for Venipuncture to Aid in Promoting More Effective Simulation Education. J Blood Disorders Transf 5: 228. doi: 10.4172/2155-9864.1000228

Page 6 of 7

maximum angle of $56^{\circ}$ was observed with a $20 \mathrm{ml}$ syringe.

This study estimated the distance travelled by the needle. Using a $38-\mathrm{mm}$ long needle, the length of needle entering the model was greatest with the $2.5 \mathrm{ml}$ syringe at $15.4 \mathrm{~mm}$ ( $40.5 \%$ of the needle), while with a $20 \mathrm{ml}$ syringe, the needle travelled $12.1 \mathrm{~mm}$ (31.8\% of the needle). Using the $20 \mathrm{ml}$ syringe as reference, the $2.5 \mathrm{ml}$ syringe travelled 3.3 $\mathrm{mm}$ further. Despite remarkable advances in technology and laboratory automation, laboratory tests still have a high degree of pre-analytical variability. 23G needles, if handled correctly, will not introduce any statistically or clinically significant errors in measurement compared with $21 \mathrm{G}$ needles [21].

Needle stick injuries expose healthcare providers to dangerous blood borne pathogens, including human immunodeficiency, hepatitis $\mathrm{B}$, and hepatitis $\mathrm{C}$ viruses. When using proactively designed safety I.V. catheters, nurses often experienced difficulties with needle insertion due to the size and overall design of the device [22]. Syringes made by different companies have variable size and it is important that simulation training uses the same venipuncture device used in the clinical situation. It is therefore important that optimal techniques incorporating different venipuncture equipment are investigated.

\section{Accurate puncture point}

For the puncture, it is essential to place the needle exactly on the point that has been selected. During blood sampling, the puncture site is determined by palpating the vein on the skin surface. The needle is then inserted without placing any mark on the chosen site. When blood was drawn in this study using a $20 \mathrm{ml}$ syringe, the greatest difference between 5 puncture points was $21 \mathrm{~mm}$, with a mean difference of 5 $\mathrm{mm}$. This distance was larger than the diameter of the vein used in the simulation. Practicing accurate insertion into a target point is therefore necessary.

\section{Accurate needle movement}

A simulator can evaluate needle movement during venipuncture carried out by a nurse. By following MP joint movement, we showed that needle hub and hand movements were inconsistent in some cases. The study encoded the movement of the $\mathrm{X}$ - and $\mathrm{Y}$-axes symbolic descriptors. If the $\mathrm{X}$-axis was I and the $\mathrm{Y}$-axis was $\mathrm{I}$, this indicated that the needle moved uniformly over a fixed distance from the time the needle tip made contact until it reached the vein.

The so-called puncture described in textbooks involves making a puncture with the $\mathrm{X}$-axis at $\mathrm{I}$ and the $\mathrm{Y}$-axis at $\mathrm{V}$ or $\mathrm{N}$, entering the vein, and then pushing the needle into the vein. However, when considering cases in which the needle moves in an intricate manner, both the hand and the needle rotate. Even when the multiple puncture points were close to each other, both needle and MP joint movements changed during puncture. The position of the needle bore did not necessarily move upward if the hand joint moved. When the needle was turned more than necessary, this had adverse effects on the puncture site.

Simulation training requires participants to be conscious of not making unnecessary movements caused by hand rotation, with the aim of ensuring the trajectory of the needle reduces stress on the puncture site.

\section{Conclusions}

This study emphasizes the importance of learning the basic movements of needle insertion at a single point and not twisting the needle or hand more than is necessary. During the initial stages until perception of the needle tip is acquired, there is no need to practice on patients, but instead use simulated arm models.

To the best of our knowledge no other study has compared differences in puncture angle and the longer distances travelled by the needle according to the size of the equipment. It is therefore necessary to account for differences in equipment when examining different venipuncture techniques.

Hand rotation may also cause rotation of the needle bore. Our results suggest that simulators may be useful for practicing needle insertion into the same puncture site and for avoiding twisting the hand more than necessary when performing venipuncture on actual patients.

Venus cannulation is one of the main procedures carried out by nurses. For the safety of patients and nurses it is important that this skill is performed in a proper and responsible way. The need for adequate education of this skill is therefore essential [23]. By using a simulator we were able to evaluate the technique using different appliances under the same conditions. A precise skill will be achieved by nurses, leading to improved patient safety. Because of establishing skill evaluation, educational relationships will also be improved.

\section{References}

1. Woolley NN, Jarvis $Y$ (2007) Situated cognition and cognitive apprenticeship: a model for teaching and learning clinical skills in a technologically rich and authentic learning environment. Nurse Educ Today 27: 73-79.

2. Baxter P, Akhtar-Danesh N, Valaitis R, Stanyon W, Sproul S (2009) Simulated experiences: nursing students share their perspectives. Nurse Educ Today 29 : 859-866.

3. Nehring WM (2008) U.S. boards of nursing and the use of high-fidelity patient simulators in nursing education. J Prof Nurs 24: 109-117.

4. Larew C, Lessans S, Spunt D, Foster D, Covington BG (2006) Innovations in clinical simulation: Application of Benner's theory in an interactive patient care simulation. Nurs Educ Perspect 27: 16-21.

5. Durham CF, Sherwood GD (2008) Education to bridge the quality gap: a case study approach. Urol Nurs 28: 431-438, 453.

6. Milisen K, De Busser T, Kayaert A Abraham I, de Casterlé BD (2010) The evolving professional nursing self-image of students in baccalaureate programs: a cross-sectional survey. Int J Nurs Stud 47: 688-698.

7. Hauber RP. Cormie E, Whyte J (2010) An exploration of the relationship between knowledge and performance-related variables in high-fidelity simulation: designing instruction that promotes expertise in practice. Nurs Educ Perspect 31: 242-246.

8. Engum SA, Jeffries P, Fisher L (2003) Intravenous catheter training system: computer-based education versus traditional learning methods. Am J Surg 186 $67-74$

9. Ricketts B (2011) The role of simulation for learning within pre-registration nursing education - a literature review. Nurse Educ Today 31: 650-654.

10. Issenberg SB, McGaghie WC, Petrusa ER, Lee Gordon D, Scalese RJ (2005) Features and uses of high-fidelity medical simulations that lead to effective learning: a BEME systematic review. Med Teach 27: 10-28.

11. Fujii C, Ishii H, Takanishi A (2013) Safe venepuncture techniques using vacuum tube system. Int J Nurs Pract 19 Suppl 3: 11-19.

12. Solis J, Oshima N, Ishii H, Matsuoka N, Hatake K, et al. (2008) Towards understanding the suture/ligature skills during the training process using WKS2RII. Int J CARS 3: 231-239

13. Rhodes ML, Curran C (2005) Use of the human patient simulator to teach clinical judgment skills in a baccalaureate nursing program. Comput Inform Nurs 23: 256-262.

14. Nicol M, Freeth D (1998) Assessment of clinical skills: a new approach to an old problem. Nurse Educ Today 18: 601-609.

15. Lee LY, Lee JK, Wong KF, Tsang AY, Li MK (2010) The establishment of an integrated skills training centre for undergraduate nursing education. Int Nurs Rev 57: 359-364. 
Citation: Fujii C, Ishii H, Takanishi A (2014) A Comparison of the Effects of Different Equipment used for Venipuncture to Aid in Promoting More Effective Simulation Education. J Blood Disorders Transf 5: 228. doi: 10.4172/2155-9864.1000228

16. Pacsi AL (2008) Human simulators in nursing education. J N Y State Nurses Assoc 39: 8-11.

17. Buckley S, Coleman J, Davison I, Khan KS, Zamora J, et al. (2009) The educational effects of portfolios on undergraduate student learning: a Best Evidence Medical Education (BEME) systematic review. BEME Guide No. 11. Med Teach 31: 282-298.

18. Andreatta P, Gans-Larty F, Debpuur D, Ofosu A, Perosky J (2011) Evaluation of simulation-based training on the ability of birth attendants to correctly perform bimanual compression as obstetric first aid. Int J Nurs Stud 48: 1275-1280.

19. Jeffries PR, Beach M, Decker SI, Dlugasch L, Groom J, et al. (2011) Multi-center development and testing of a simulation-based cardiovascular assessment curriculum for advanced practice nurses. Nurs Educ Perspect 32: 316-322.
20. Chow J, Rayment G, Wong J, Jefferys A, Suranyi M (2009) Needle-stick injury a novel intervention to reduce the occupational health and safety risk in the haemodialysis setting. J Ren Care 35: 120-126.

21. Lippi G, Salvagno GL, Montagnana M, Brocco G, Cesare Guidi G (2006) Influence of the needle bore size used for collecting venous blood samples on routine clinical chemistry testing. Clin Chem Lab Med 44: 1009-1014.

22. Shelton P, Rosenthal K (2004) Sharps injury prevention: select a safer needle. Nurs Manage 35: 25-31.

23. Bitsika E, Karlis G, lacovidou N, Georgiou M, Kontodima P, et al. (2014) Comparative analysis of two venipuncture learning methods on nursing students. Nurse Educ Today 34: 15-18. 